\section{OPEN JOURNAL SYSTEMS}

ISSN:2237-2202
Available on line at Directory of Open Access Journals

Journal of Hyperspectral Remote Sensing v.9, n.6 (2019) 353-360

www.periodicos.ufpe.br/revistas/jhrs

\section{Journal of Hyperspectral Remote Sensing}

www.ufpe.br/jhrs

\title{
Empiric forecasting of dominant modes to summer precipitation anomaly of Northeast Brazil
}

\author{
Rodrigo L. da Rocha Júnior", Fabrício D. dos S. Silva**, Rafaela L. Costa***, Heliofábio B. Gomes ${ }^{* * * * *}$ \\ "Master Student in the Postgraduate Program in Meteorology -PPGMET/ICAT/UFAL. Email: rrodrigo.junior@ hotmail.com \\ (Corresponding author) \\ *** Prof. Dr in the Postgraduate Program in Meteorology - PPGMET/ICAT/UFAL. Email: fabricio.santos@icat.ufal.br \\ ***:PNPD Scholarship in the Postgraduate Program in Meteorology -PPGMET/ICAT/UFAL. Email: rafaelalisboac@gmail.com \\ *****Prof. Dr in the Postgraduate Program in Meteorology -PPGMET/ICAT/UFAL. Email: heliofabio@ @icat.ufal.br
}

Received 16 September 2019, accepted 9 October 2019

\begin{abstract}
The main economic activities of the Brazilian Northeast (NEB) are affected by the region's highly variable climate, requiring research into seasonal climate forecasting. In this work we show the results obtained after analyzing the relationship between the main modes of NEB rainfall variability and lagged oceanic and atmospheric variable fields, that is, preceding rainfall. Consistent relationships were found between sea surface temperature (SST) in the Equatorial Pacific, Equatorial Atlantic and South Atlantic with NEB rainfall. Rossby wave patterns over the North Pacific that propagate from west to east to the Intertropical Convergence Zone (ITCZ), Walker Cell and Upper Bolivia have also been identified. In this research, the main objective was to identify the physical basis for the construction of linear regression models capable of predicting seasonal summer rainfall in the NEB, from the relationships between predictor-predictor. The adjusted regression model performed well between simulations and observations, based on validation metrics and can be reliably indicated for operational climate forecasting systems.

Keywords: seasonal forecast, climate, precipitation, reliability
\end{abstract}

\section{Introduction}

Climate variability directly influences human activities. Problems related to human exposure to weather conditions can be mitigated by strategic actions taken on the basis of seasonal climate forecasts (eg climate forecasts for the next three months). With the advancement of climate modeling and seasonal climate prediction (SCP) and its practical use, the benefits of its proper use could be measured in the literature. Roger et al. (2000) showed that the integration of SCP and agricultural models contributed substantially to the agricultural planning of Northeast Australia. Podesta et al. (2002) showed that the use of PS provided agricultural return to rural producers in the Pampean region of Argentina, providing information for alternating sowing, nitrogen application, plant density and hybrid cultivation; making cultivation economically viable. In the area of electricity production, private companies specializing in energy trading use seasonal and subseasonal forecasts to gain prospects for the inflow of reservoirs that will influence the affluent natural energy.

Climate plays a key role in NEB. Half of Brazil's family farms are concentrated in NEB. This activity contributes significantly to the region's economy, especially in the semiarid sector located in the central portion of the NEB. The frequent occurrence of drought, together with other social and political factors, causes supply crises, soil degradation, crop losses and rural exodus. By extension, the region's electricity production is affected, as part of NEB's energy matrix comes from hydroelectric plants. In the coastal sector of the region, natural beauties drive tourism, which is responsible for the local economy. These areas depend considerably on climatic conditions and SCP is a very useful tool for better strategic management of the above mentioned areas.

Empirical models (EM) of SCP have evolved substantially due to improved quality, range and diversity of atmospheric and oceanic observations. van den Dool. (2006) through theoretical and observational experiments demonstrates the predictability of climate is associated with the dominance of linear climate terms (low frequency variability) over nonlinear terms (high frequency variability). According to the author, EM and dynamic models are capable of solving linear terms.

In this scenario, just as dynamic models need new developments, EMs and statistical procedures for combining forecasts from dynamic models also have the potential for further advances. In recent years new statistical procedures have emerged with paradigms applied to structures inherent to climate time series and application of new computationally intensive methods of parameter estimation. Xing et al. (2016a) compared results obtained by a partial regression 
model employing the least squares method and empirical orthogonal functions with a set of 5 coupled dynamic models. Although with modest dexterity, the statistical combination procedures surpassed the simple average set of the dynamic models. (AghaKouchak et al., 2016; Madagdar et al.,2016) developed a statistical-dynamic hybrid model system for drought forecasting in the southwestern United States. The model uses the Expert Advice algorithm to unite the joint prediction of eight dynamic models and the prediction of a conditional probability Bayesian EM. Wu et al. (2018) obtained consistent results by validating inverse linear and trend models for seasonal precipitation prediction in Peru. Gavrilo et al. (2018) obtained satisfactory results with a SST prediction model based on the linear decomposition of the dynamic modes of variability of the Equatorial Pacific SST. The model evolution operator was estimated by Bayesian approximation. In Brazil, some works were performed with the objective of uniting techniques and model classes. Lucio et al. (2010) validated the joint and stochastic model of the Brazilian Meteorological Institute (INMET), based on time series autoregressive modeling methods, canonical correlations and exponential smoothing. Coelho (2010) combined an empirical model based on singular value decomposition with three dynamic models within the EURO-Brazilian Initiative for Improving South American Seasonal Forecasts (EUROBRISA).

In this article, we will show the results obtained by an analysis of the relationship between the main modes of precipitation variability in the Brazilian Northeast (NEB) and lagged oceanic and atmospheric variable fields, that is, preceding precipitation. Subsequently, these relationships were used to adjust an empirical seasonal forecasting model applied to the NEB domain. This research aims to apply this modelling to verify the predictive potential of the accumulated rainfall of the January-FebruaryMarch (JFM) quarter, an important period with significant NEB precipitation volumes, especially the northern sector.

\section{Materials and methods}

We used the Global Precipitation Climatology Project (GPCP, v2.2) monthly average precipitation product that integrates surface station observations and satellite estimation into a grid with a resolution of $2.5^{\circ} \times 2.5^{\circ}$. SST data is from Extended Reconstructed Sea Surface Temperature version 5 (ERSSTv.5) which is a product derived from the International Comprehensive Ocean-Atmosphere Dataset (ICOADS) (Huang et al., 2017). The SST grid has a resolution of $2 \times 2^{\circ}$. We used the variables geopotential height at $500 \mathrm{mb}$, omega at $850 \mathrm{mb}$, southern (VV) and zonal (VU) wind components at 850 and $300 \mathrm{mb}$ from NCEP reanalysis 1 , with a resolution of $2.5^{\circ} \times 2.5^{\circ}$. The anomaly of all variables was calculated taking the period 1981-2010 as a reference.

The model discussed here is based on the method proposed by Wang et al. (2007) called Predictive Mode Analysis (PMA). After Wang the method was studied by Xing et al. (2014), Yim et al. (2014), Wang et al. (2015), Xing et al. (2016b). The method consists of decomposing precipitation anomaly (APREC) data by empirical orthogonal functions (EOF) to obtain modes that represent predictable climate variability. Each mode was correlated with lagged atmospheric fields to check for statistically robust relationships with the potential to provide advance information for forecasting. Additionally, the relationships found were investigated to find physical explanations associated with the modes. The lag between the predictor fields (SST and atmospheric circulation variables) and the predicted field to be predicted (precipitation) is always two months or more, aiming to adjust the model under forecast conditions.

From the analysis made, we choose physically relevant atmospheric fields for the prediction of each mode. Linear regression models were adjusted for individual prediction of each mode. For each field chosen, a representative index is generated to be used as an independent variable in regression models. The indices were generated by the method proposed by Xing et al. (2016a). Each model is cross-validated throughout the analysis period (1980-2016). For the stability of the parameters of each model, we chose not to use more than two indexes per model. The indices are chosen by mode correlation analysis and by analysis of variance inflation factor (VIF), which should not exceed 4.

The APREC values at each point were reconstructed by a linear combination of the predicted modes with the eigenvectors obtained in the EOF analysis. The model performance is measured by the Pearson correlation coefficient and root mean square error.

\section{Results and discussion}

The first four precipitation modes derived from the analysis were chosen. This decision took into account well-defined spatial patterns (Figure 1) and concentrated $80 \%$ of the total data variability. The modes chosen account for $42 \%, 24 \%, 8 \%$ and $6 \%$ of the variability, respectively. From the analyzed fields, for each mode, the two most significant fields will be shown. Image 1 shows the spatial distribution of the eigenvectors obtained in the EOF analysis. Opposite signs between rotational and correlation values means 
inverse linear relationship. Equal signs means direct 1

(a) Mode 1

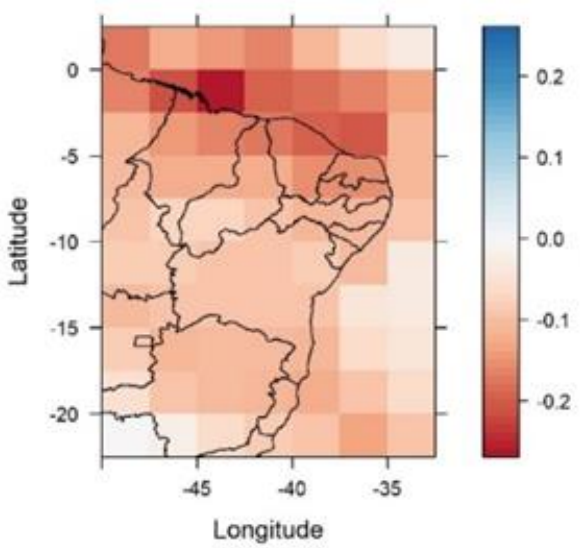

(c) Mode 3

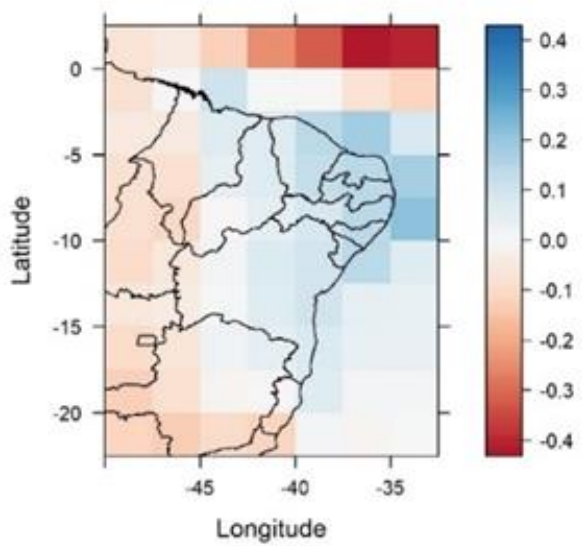

linear relationship.

(b) Mode 2

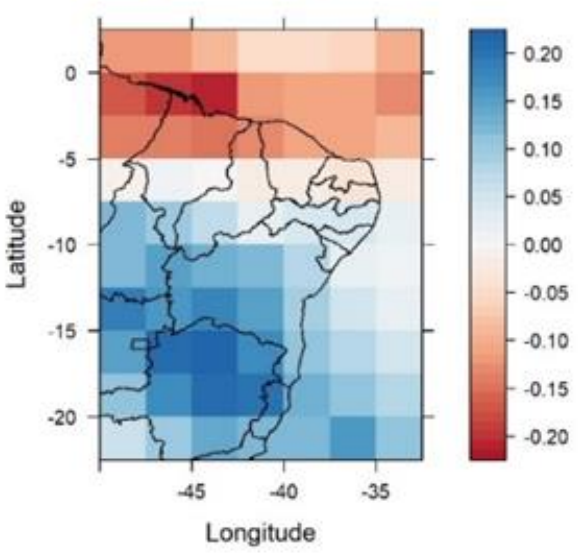

(d) Mode 4

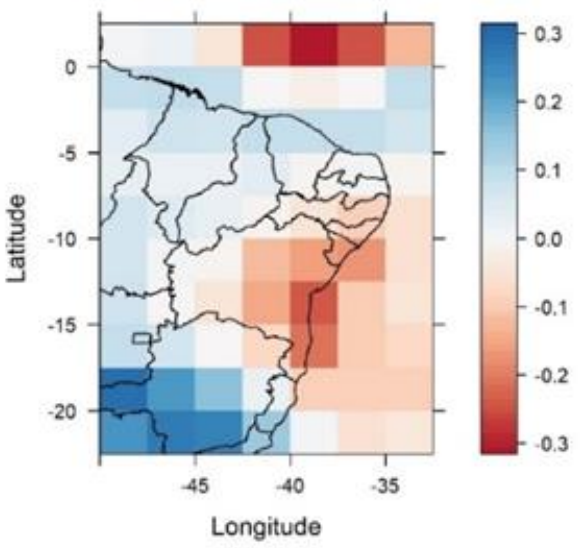

Figure 1 - Spatial distribution of eigenvalues of the first four modes (a, b, c and d) of January-February-March precipitation anomaly.

Mode 1

High-level SST and VV anomalies showed a better relationship with mode 1 . In the wind field (Figure 2a) it is possible to notice the propagation of Rossby wave trains in the northern hemisphere. Zou et al. (2013) studied the influence of these waves on the Asian summer monsoon. According to these authors, this wave train is induced by the North Atlantic tripole and has a barotropic structure. The waves are generated by thermal factors in the tripole region and propagate from west to east to Asia. We hypothesized that this is an indirect influence of this North Atlantic region on the Brazilian Northeast. It is possible to observe that there is a pattern of latitudinal bubbles in the North Pacific with centers more correlated with precipitation anomaly (Figure 2a). The position of the bubbles represents the path region of the wave propagation and the centers represent the central axis of the average propagation path. Waves positioned further west appear more correlated with mode 1, indicating that they will reach South America in
January. In the image it is also possible to observe the direction of propagation that tends to go to the southern hemisphere. These waves act as dynamic forcing that modify the position of the Intertropical Convergence Zone (ITCZ), this is confirmed by observing the mode 1 spatial pattern (Figure 1) that concentrates the highest energy over the north of Northeast.

In the TSM anomaly field (Figure 2b) it is possible to notice the relevance of the tropical Atlantic over mode 1. The Atlantic dipole is characterized in the map, with greater relevance of the south equatorial Atlantic. The equatorial Pacific region shows a faint pattern that can be associated with El Niño-Southern Oscillation (ENSO). However, for mode 1 indices, this region will have little or no relative importance. The Atlantic region acts as a thermal forcing that modulates ITCZ's position and provides power for maintaining the cloud range. Wave action on NEB precipitation depends on the phase, while the increase in SST increases precipitation. 

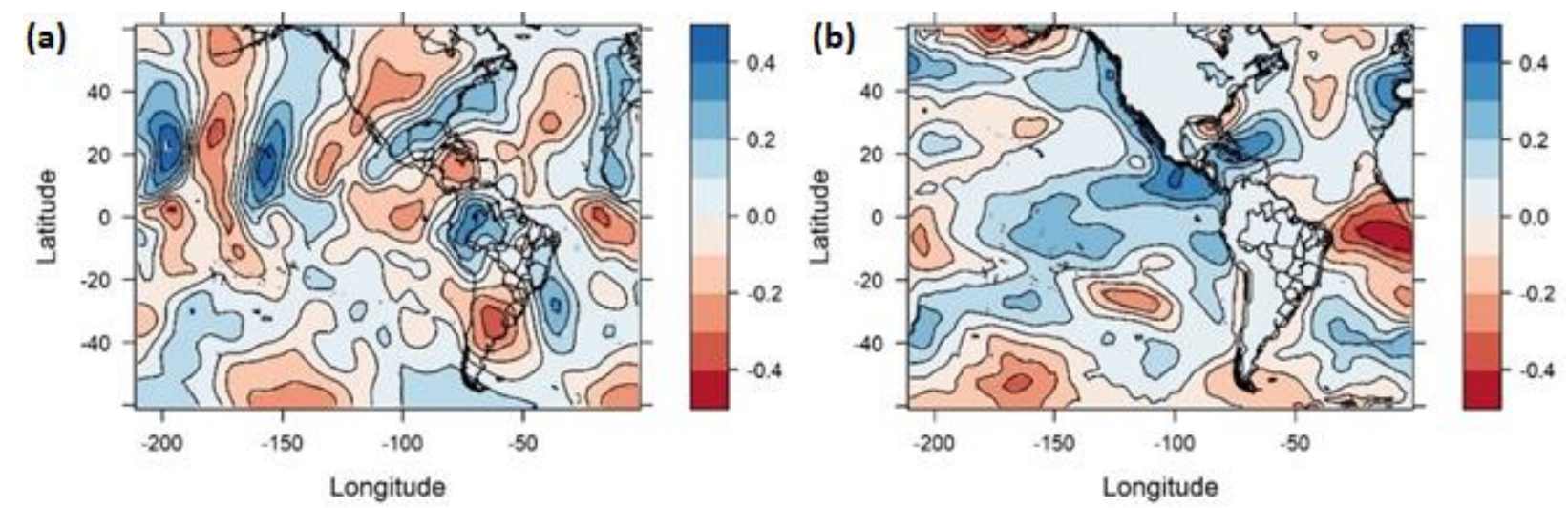

Figure 2 - Correlation between the main component (time series) associated with mode 1 of the Empirical orthogonal functions analysis of January-February-March precipitation anomalies with (a) southern wind anomaly at the 300 $\mathrm{mb}$ level in the previous November and (b) SST anomaly also from the previous November.

\section{Mode 2}

Looking at the image in Figure $3 \mathrm{a}$, the consistency of mode 2 with the equatorial Pacific is remarkable. The distribution of the eigenvalues of mode 2 (Figure 1) has two opposite regions. According to the analysis, in the north (south-center) of NEB, SST in the Pacific causes decrease (increase) of precipitation. Observing the variability of mode 2 (Figure 4) it is possible to notice that from 1985 onwards the series remains below average and approximately in 2002 it assumes an increasing trend, remaining above average. This indicates that this mode has a decadal variability.

The omega field (Figure 3b) shows no visible uniform pattern, but the index generated with this field obtained a correlation of 0.85 with mode 2 . This consistent relationship could not be ignored. It is possible to see a line formed over the equatorial Pacific on the eastern side, matching the link with the SST in that region. Due to the strong correlation of this field with mode, the index generated with this variable was chosen as the only mode 2 predictor.
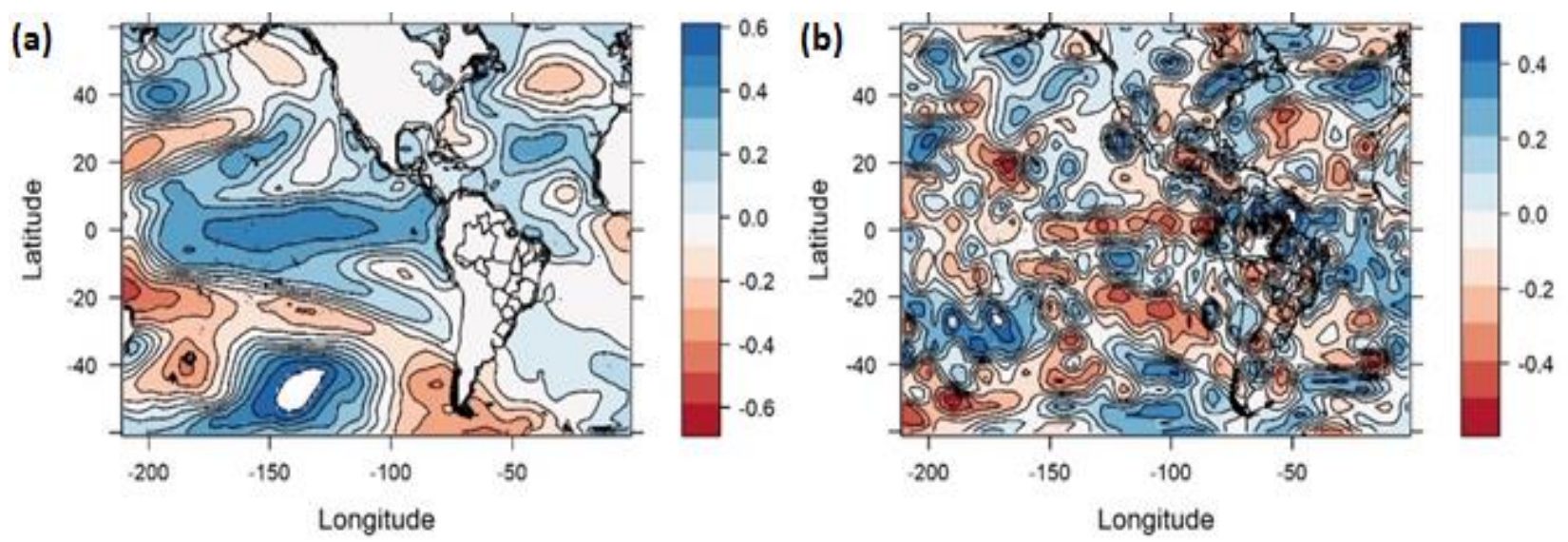

Figure 3 - Correlation between the main component (time series) associated with mode 2 of the Empirical orthogonal functions analysis of January-February-March precipitation anomalies with (a) sea surface temperature anomaly and (b) omega at $850 \mathrm{mb}$, both for the previous November. 


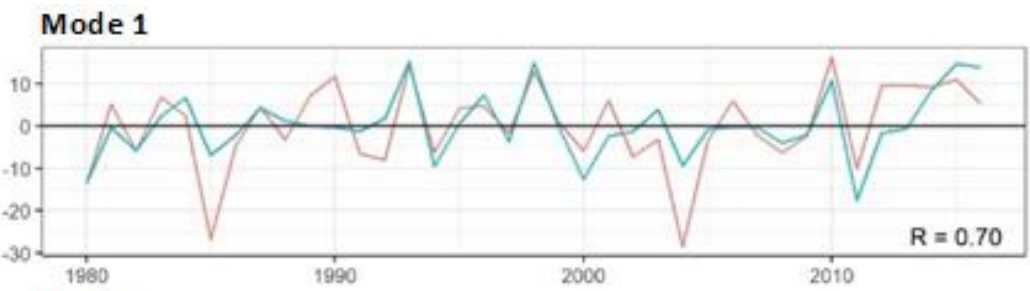

- Observed

- Predicted

Mode 2

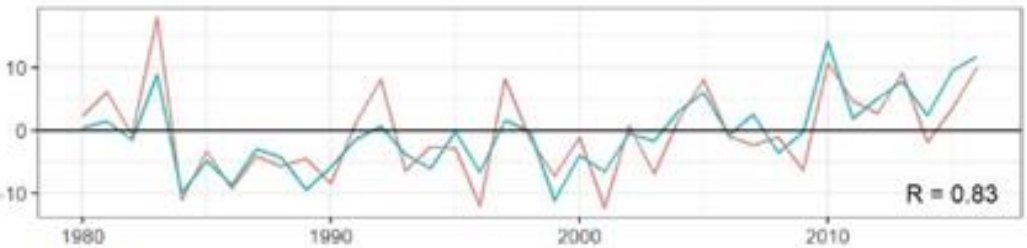

- Observed

- Predicted

Mode 3

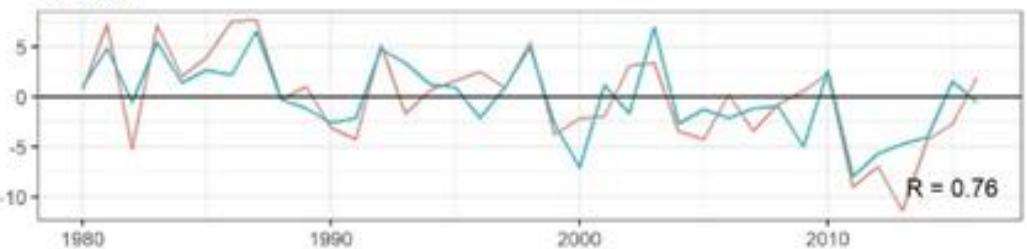

- Observed

- Predicted

Mode 4

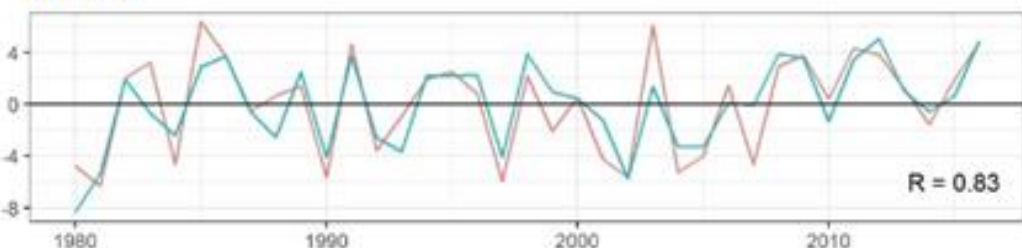

- Observed

- Predicted

Figure 4 - Observed and predicted time series for each January-February-March precipitation mode, with the zero axis highlighted and correlations obtained for each model.

Mode 3

In Figure 5a it can be noted that the SST of the Atlantic off the coast of Colombia, Venezuela and Guyana correlates well with precipitation mode 3. There are also evident relationships in the Pacific, with a negative horseshoe-shaped relationship between $40^{\circ} \mathrm{N}$ and $40^{\circ} \mathrm{S}$ and a positive correlation range between $40^{\circ} \mathrm{S}$ and $60^{\circ} \mathrm{S}$. From the temporal analysis of the mode (Figure 4), it is possible to notice that the mode has an interannual variability. In Central America, by the $300 \mathrm{mb}$ zonal wind field (Figure 5b), there appears to be a relationship between the Pacific and the Central Atlantic. This pattern is probably associated with the Walker cell, as it is remarkable that this pattern observed in the wind field over Central America coincides with a longitudinal gradient observed between the Pacific and Equatorial Atlantic (Figure 5a). The mode 3 spatial pattern (Figure 1) points to a decrease in precipitation in most NEB with the increase (decrease) of the Atlantic (Pacific) SST. While the western end of the region has increased precipitation with increasing (decreasing) SST in the Atlantic (Pacific).
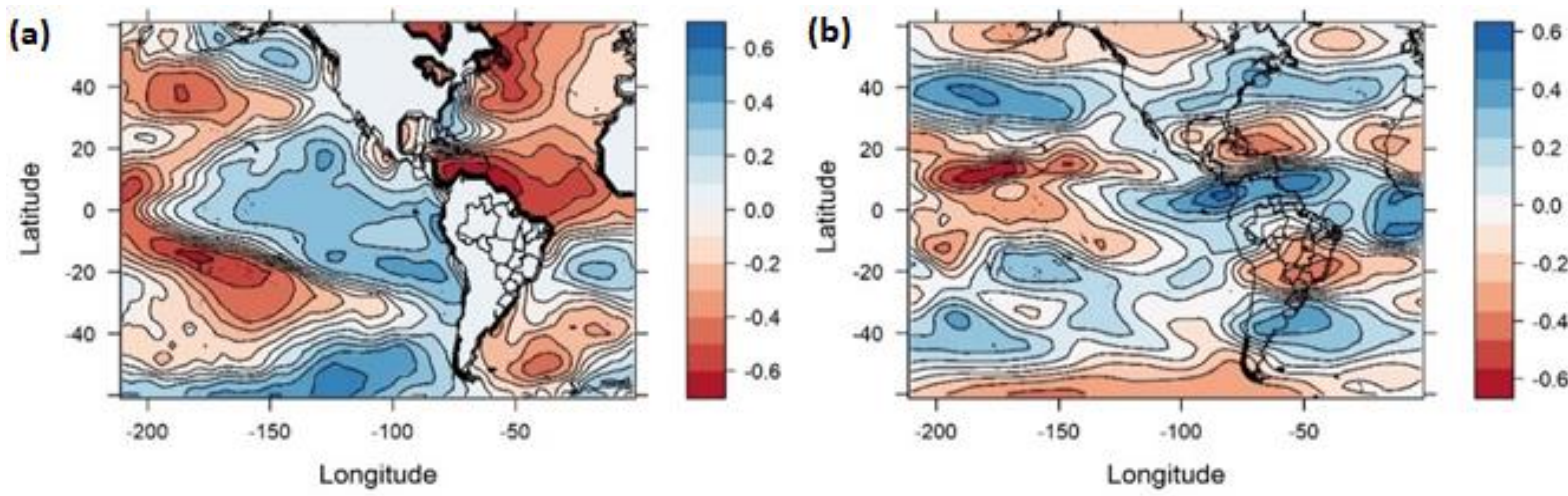

Figure 5 - Correlation of mode 3 of the precipitation anomaly with (a) anomaly of the sea surface temperature and (b) zonal component of the wind in $300 \mathrm{mb}$, both for the month of November. 


\section{Mode 4}

Observing Figures 6a and 6b, it is evident the presence of wave patterns in the southern hemisphere, both in the SST field and in the zonal wind field. The observed waves in the wind field appear to be connected with centers found in the SST field. In the wind field (Figure $6 \mathrm{~b})$ there is a negative core $\left(10^{\circ} \mathrm{S}\right.$ $0^{\circ}, 100^{\circ} \mathrm{W}-50^{\circ} \mathrm{W}$ ) positioned in central South America that coincides with the climatic position of the Bolivian Alta. In parallel, for both fields, there is a negative nucleus in the South Atlantic $\left(20^{\circ} \mathrm{S}-40^{\circ} \mathrm{S}\right.$, $\left.40^{\circ} \mathrm{W}-0^{\circ}\right)$ that coincides with the climatological position of the South Atlantic Subtropical High (ASAS). Assuming the relationship of the wind field in central South America $\left(10^{\circ} \mathrm{S}-0^{\circ}, 100^{\circ} \mathrm{W}-50^{\circ} \mathrm{W}\right)$ and South Atlantic TSM $\left(20^{\circ} \mathrm{S}-40^{\circ} \mathrm{S}, 40^{\circ} \mathrm{W}-0^{\circ}\right)$, it is observed that the intensification of ASAS causes more rain in the sector. NEB and less rain in the other sectors of the region.
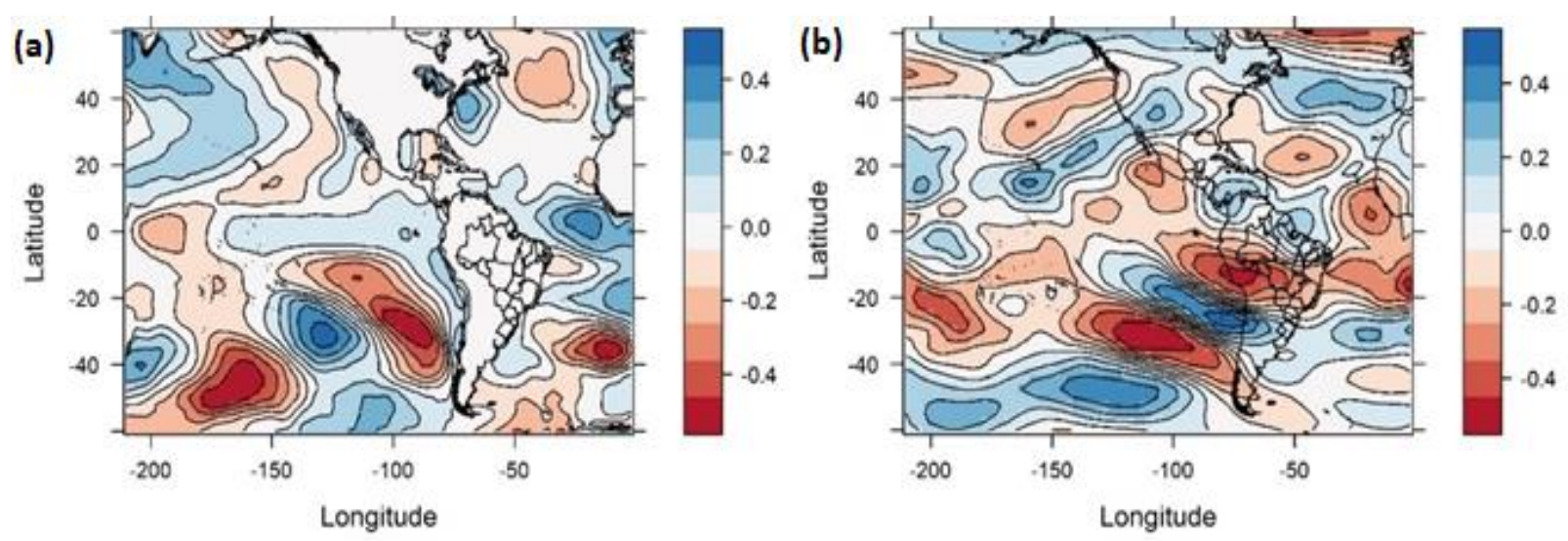

Figure 6 - Correlation of mode 4 of the precipitation anomaly with (a) anomaly of the sea surface temperature and (b) zonal component of the wind in $300 \mathrm{mb}$, both for the month of November.

\section{Predictability of Modes}

Given the physically found relationships for the four precipitation anomaly modes, it was possible to adjust regression models to predict each mode using the indices created. Figure 4 illustrates the result of cross-validation performed for the four modes chosen. In general the predictions are good and in many moments the model can describe the peaks of the series. It is interesting to note that the omega field is a great predictor of mode 2, even showing a special uneven pattern.

Throughout the NEB domain, the correlations obtained were statistically significant by the t-student test at a level of $5 \%(r>0.33)$. The dexterity achieved by the model is linked to the spatial patterns found in the EOF analysis. The southern NEB sector achieved the best domain performance. Both in terms of correlation and RMSE. Looking at Figure 1, it is possible to notice that in the southern sector is the energy center of modes 2 and 4 . The northwest sector of NEB also presents high correlation values (Figure 7a) by concentrating the energy centers of modes 1 and 2 (Figure 1). However, the RMSE values for northern NEB were high compared to the rest of the domain, indicating that the model is being naive in representing the variability linked to the performance of the ITCZ in the region. Every coastline is under the influence of mode 3 and further north over the influence of mode 4 (Figure 1). The central NEB region has the lowest dexterity observed (Figure 7). This region is at a transitional point anyway. EOF patterns concentrate little relative energy for the region (Figure 1). Because it is a locality that is exposed to all modes, but not so significantly, the internal (not predictable) variability of this region overlaps the signals of external variability that the model tries to predict. On the other hand, the lowest observed RMSE is in this sector. This sector has a dry and little variable climate, which explains the low RMSE. 

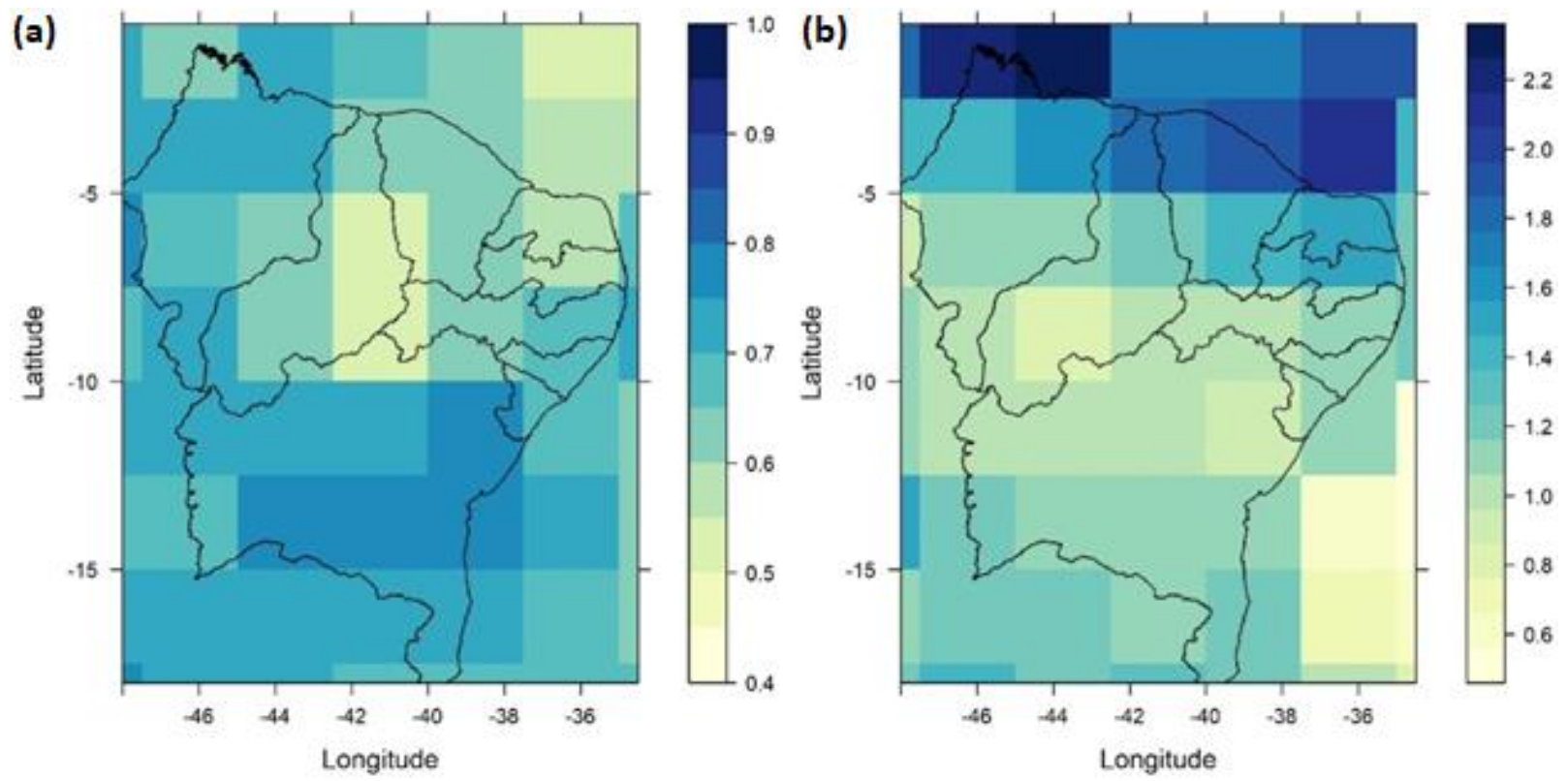

Figure 7 - Verification fields for the empirical prediction of precipitation anomaly at Jan-Feb-Mar station. Pearson's correlation in the field (a) and Root Mean Square Error (RMSE) in the field (b).

\section{Conclusions}

In this work we applied the methodology of Analysis of Predictable Modes on the Northeast region in the precipitation forecast of the January-FebruaryMarch quarter. The analysis of the TSM fields showed thermal connections with well defined patterns linked to the Atlantic and Pacific oceans. Mode 1 is associated with SST anomalies in the North and South Atlantic, with the South Atlantic being the most important. Mode 2 was associated with SST in the Equatorial Pacific with a decadal oscillation. Mode 3 is linked to a longitudinal temperature gradient between the Pacific and the Atlantic. Mode 4 is associated with temperature anomalies that provide power for atmospheric circulation anomalies. The wind fields derived from the analysis exhibited anomalous atmospheric circulation patterns of different natures. Mode 1 is linked to Rossby wave propagation in the Northern Hemisphere. Mode 3 is linked to Walker circulation in the equatorial region and mode 4 is linked to stationary atmospheric circulation anomalies. Some of these stationary anomalies have been associated with the Bolivian High and the South Atlantic Subtropical High. The physical links are consistent and the indices generated with the fields derived from the analysis are significantly correlated with their respective modes.

The prediction of the modes by linear regression using the indices as explanatory variable was efficient for all modes. Highlight for mode 2, which is very consistently explained by the omegafield index at 850 . The empirical model has been shown to be functional within the seasonal forecast and can be used operationally over the NEB domain to support the region's economic activities.

\section{Acknowledgements}

The present work was carried out with the support of the Higher Education Personnel Improvement Coordination - Brazil (CAPES). The first author thanks the granting of the Master's scholarship and the third author is grateful for the grant of the Post Doctorate scholarship at ICAT/UFAL.

\section{References}

AghaKouchak, A., Madadgar, S., Shukla, S., Cheng, L., Hsu, K.L., 2016. Improving seasonal drought prediction in California by combining statistical and dynamical models. AGU Fall Meeting Abstracts.

Coelho, C.A.S., 2010. A new hybrid precipitation seasonal forecasting system for South America. Congresso Brasileiro de Meteorologia, Belém.

Gavrilov, A., Seleznev, A., Mukhin, D., Loskutov, E., Feigin, A., Kurths, J., 2019. Linear dynamical modes as new variables for data-driven ENSO forecast. Climate Dynamics 52, 2199-2216.

Huang, B., Thorne, P.W., Banzon, V.F., Boyer, T., Chepurin, G., Lawrimore, J.H., Menne, M.J., Smith, T.M., Vose, R.S., Zhang, H-M., 2017. Extended reconstructed sea surface temperature, version 5 (ERSSTv5): upgrades, validations, and intercomparisons. Journal of Climate 30, 81798205.

Lucio, P.S., Silva, F.D.S., Fortes, L.T.G., Santos, L.A.R., Ferreira, D.B., Salvador, A.M., Balbino, 
H.T., Sarmanho, G.F., Santos, L.S.F.C., Lucas, E.W.M., Barbosa, T.F., Dias, P.L.S., 2010. Um modelo estocástico combinado de previsão sazonal para a precipitação no Brasil. Revista Brasileira de Meteorologia 25, 70-87.

Podesta, G., Letson, D., Messina, C., Royce, F., Ferreyra, R.A., Jones, J., Hansen, J., Llovet, I., Grondona, M., O'Brien, J.J., 2002. Use of ENSOrelated climate information in agricultural decision making in Argentina: a pilot experience. Agricultural Systems 74, 371-392.

Roger, C., Graham, S., de Hoedt C., 2000. The development and delivery of current seasonal climate forecasting capabilities in Australia. TermoIn: Hammer, Graeme et al. Applications of seasonal climate forecasting in agricultural and natural ecosystems. Springer Science \& Business Media, 21, 67-75.

van den Dool, H., 2007 Empirical Methods in ShortTerm Climate Prediction. Oxford University Press, New York.

Wang, B., Lee, J.Y., Kang, I.S., Shukla, J., Hameed, S.N., Park, C.K., 2007. Coupled predictability of seasonal tropical precipitation. CLIVAR Exchanges 12, 17-18.

Wang, B., Lee, J-Y., Xiang, B., 2015. Asian summer monsoon rainfall predictability: a predictable mode analysis. Climate Dynamics 44, 61-74.

Wu, S., Notaro, M., Vavrus, S., Mortensen, E., Montgomery, R., Piérola, J., Block, P., 2018. Efficacy of tendency and linear inverse models to predict southern Peru's rainy season precipitation. International Journal of Climatology 38, 25902604.

Xing, W., Wang, B., Yim, S-Y., 2016a. Long-Lead Seasonal Prediction of China Summer Rainfall Using an EOF-PLS Regression-Based Methodology. Journal of Climate 29, 1783-1796.

Xing, W., Wang, B., Yim, S-Y., 2016b. Peak-summer East Asian rainfall predictability and prediction part I: Southeast Asia. Climate Dynamics 47, 1-13.

Yim, S-Y., Wang, B., Xing, W., 2014. Prediction of early summer rainfall over South China by a physical empirical model. Climate Dynamics 43, 1883-1891. 